\title{
Ação afirmativa na Índia e no Brasil: um estudo sobre a retórica acadêmica
}

JOÃO FERES JR."

VERÔNIGA TOSTE DAFLON **

\section{Resumo}

Políticas de ação afirmativa têm sido aplicadas para resolver problemas sociais e políticos derivados da persistência de padrões sociais de desigualdade e discriminação em diversos países. Embora sejam comumente associadas aos Estados Unidos, as ações afirmativas foram aplicadas pioneiramente pela Índia, durante a década de 1950, quando a Constituição estabeleceu cotas nas legislaturas, no emprego público e no ensino superior para as Scheduled Castes e Scheduled Tribes. O Brasil, por sua vez, começou a adotar cotas na admissão às universidades para pretos, pardos e pobres apenas em 2003. A despeito de suas trajetórias históricas distintas e das várias diferenças que caracterizam cada sociedade, os argumentos levantados por acadêmicos contra essas políticas nos dois países são idênticos ou análogos. Neste artigo, agrupamos esses argumentos em três grupos temáticos, a fim de demonstrar que eles podem ser ligados às teses conservadoras identificadas por Albert Hirschman como as do efeito perverso, da futilidade e da ameaça. Na conclusão, discutimos como esses argumentos, que são apresentados por seus autores como contribuições progressistas para o debate público, podem de fato obstruir a diminuição da discriminação e da exclusão social.

Palavras-chave: Ação afirmativa. Discriminação. Índia. Brasil. Retórica.

\footnotetext{
* Universidade do Estado do Rio de Janeiro (Brasil)

${ }^{* *}$ Universidade Federal do Rio de Janeiro (Brasil)
} 


\section{Affirmative action in India and Brazil: a study of the academic rhetoric}

\section{Abstract}

Affirmative action has been employed to solve problems derived from the persistence of inequality and discrimination in several countries. Although commonly associated with the United States, affirmative action was pioneered by India during the 1950s, when the constitution mandated reservations in legislatures, public employment and universities for Scheduled castes and Scheduled tribes. Brazil, on the contrary, adopted quotas in university admissions for blacks, browns and the poor only in 2003. Despite the differences between both countries, key arguments raised by its academics against affirmative action are identical or analogous. In this paper we group these arguments in three thematic clusters in order to demonstrate that they can be linked to the conservative theses Albert Hirschman identified as the perverse effect, futility, and jeopardy. In the conclusion we discuss how arguments which are presented as progressive contributions to the public debate might in fact stifle the mitigation of discrimination and social exclusion.

Keywords: Affirmative action. Caste. Race, India. Brazil. Rhetoric.

\section{Introdução}

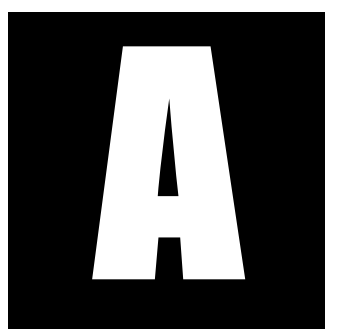

despeito do grau de desenvolvimento das ciências sociais no Brasil, os estudos comparados não constituíram aqui uma tradição de pesquisa. Isso tem mudado somente nos últimos anos, com o crescente interesse acadêmico pelos países da América do Sul e da América Latina, mesmo que os trabalhos pertencentes a essa última modalidade tendam a reproduzir os mesmos erros e simplificações de seu congênere norte-americano. Ainda mais raros são os trabalhos que comparam países do Sul Global. 
Durante muito tempo, estudos comparativos foram província quase que exclusiva da academia norte-americana e conduzidos conforme as diretrizes dos estudos de área ${ }^{1}$, atendendo em muitos aspectos aos imperativos políticos daquele país no pós-guerra. Esse paradigma começou a ser contestado após a queda da União Soviética e o fim da Guerra Fria (Prewitt, 1996), mas a mudança ainda não se completou. A presente contribuição busca expandir as possibilidades do trabalho comparativo ao abranger os casos de dois países que raramente foram estudados em conjunto, seja na academia brasileira ou alhures: Índia e Brasil. A escolha desses casos torna-se ainda mais relevante em razão da recente tendência de tratá-los, junto a China e Rússia, como um grupo de potências emergentes: os BRICS². É de conhecimento comum que, a despeito de seu crescimento econômico recente, estes países enfrentam o desafio de combater severas desigualdades econômicas e sociais. Nesse artigo enfatizaremos uma política pública que foi implementada em ambos os casos com o intuito de incluir grupos marginalizados e discriminados: as ações afirmativas.

Nosso objetivo aqui não é o de analisar os resultados dessas políticas, mas o debate travado em torno delas, e mais especificamente os argumentos que foram empregados por acadêmicos contra essas medidas, no Brasil e na Índia. Pretendemos demonstrar que em ambas as experiências os argumentos contrários às ações afirmativas podem ser classificados em torno de determinadas estratégias discursivas que se encaixam nas

\footnotetext{
${ }^{1}$ Estudos de área, area studies em inglês, é uma denominação genérica dos estudos acadêmicos especializados em regiões mundiais que se consolidaram na academia norte americana no pós-guerra. Sua consolidação foi incentivada pelo Estado e pelas fundações privadas daquele país (Arnove, 1982; Berger, 1993). Entre eles temos Latin American Studies, Sovietology, African studies, Asian studies, European studies, etc. com um sem número de divisões internas. Esse tipo de divisão por áreas orientou por muito tempo a distribuição de verbas de pesquisa e a organização de coleções de livros, periódicos e mesmo do corpo docente de departamentos acadêmicos. Especialistas de área pertencem a um amplo rol de disciplinas de ciências sociais e humanas, entre elas história, sociologia, ciência política, antropologia, línguas, estudos literários, estudos culturais, etc.

${ }^{2}$ A sigla BRICS designa um grupo de grandes países emergentes composto por Brasil, Rússia, Índia, China e África do Sul.
} 
três teses reacionárias identificadas por Albert Hirschman em seu livro $A$ retórica da intransigência: perversidade, futilidade e ameaça (1992). De acordo com Hirschman, essas teses foram historicamente mobilizadas na reação contra os avanços progressistas tais como a extensão dos direitos civis, o sufrágio universal e o advento do Estado de Bem-Estar Social. Embora o Brasil e a Índia sejam países muito diferentes em diversos aspectos, há uma grande semelhança na maneira como os argumentos de oposição à ação afirmativa figuram no debate público.

O presente texto seguirá os seguintes passos: primeiramente, proporcionamos um breve panorama dos casos brasileiro e indiano de ação afirmativa. Em sequência, apresentamos os argumentos mais incidentes nos discursos dos acadêmicos que se opõem a essas medidas. Demonstramos então como esses argumentos podem ser agrupados em estratégias e temas-chave propostos por Hirschman. Finalmente, argumentamos que argumentos dessa natureza contribuem para fazer regredir o debate acerca da discriminação e da exclusão social em ambas as sociedades.

\section{A ação afirmativa no Brasil e na Índia}

A ação afirmativa tem sido aplicada em diversos países como resposta a pressões de movimentos sociais pela elevação da qualidade de vida e das condições de mobilidade social de grupos historicamente desprivilegiados (Cahn 2002, Robinson 2001). Baseada no procedimento da discriminação positiva, essa modalidade de política pública entra em cena quando a legislação de orientação universalista se revela impotente para resolver problemas derivados da persistência de padrões sociais de exclusão e discriminação ao longo do tempo (Jaccoud, 2009). ${ }^{3}$ Em outras

\footnotetext{
${ }^{3}$ Na verdade, é possível também pensar algumas medidas de ação afirmativa como instrumentos para realizar de fato políticas universalistas. Um exemplo hipotético: para fazer com que todos os ribeirinhos de um trecho do Rio Amazonas tenham acesso à educação pública fundamental, é necessário criar um programa especial de transporte para eles.
} 
palavras, como política de caráter focal que visa à justiça social, a ação afirmativa procura romper com mecanismos inerciais de exclusão que permanecem intocados pelas políticas públicas universais ou quando estas sequer são plenamente implantadas.

Políticas de ação afirmativa podem ser definidas como provisões de alguma espécie de reparação para determinados grupos persistentemente discriminados e vítimas de exclusão socioeconômica. Em grande parte dos casos, para além do atendimento a reivindicações coletivas como distribuição de terras, de moradias, recursos escassos e proteção a certos estilos de vida, elas consistem em proporcionar vantagens competitivas para membros de grupos desprivilegiados em processos de disputa acirrada por posições sociais de prestígio (Feres Jr.; Zoninsein, 2006) ${ }^{4}$. Essa última modalidade de ação afirmativa tem como objetivo mitigar a sub-representação dessas pessoas nos estratos médios e altos de sociedades que historicamente as marginalizaram e dificultaram sua ascensão social (Weisskopf, 2004). ${ }^{5}$

Dos casos de ação afirmativa registrados, o mais antigo de que se tem notícia é o da Índia, onde a adoção de tais políticas data de 1950, e um dos mais recentes o do Brasil, que começou a implementar esse tipo de política apenas em meados de 2003. Após conquistar a independência, a Índia criminalizou o casteísmo e consagrou em sua constituição o princípio das "políticas de reserva", medidas voltadas para a proteção e

\footnotetext{
${ }^{4}$ Uma vez que estamos falando de países com democracias representativas liberais, ou seja, capitalistas, o termo "vantagens competitivas" é adequado dado que a autorrealização de uma pessoa depende em grande medida das oportunidades (vantagens) que esta obtém durante a vida.

${ }^{5}$ As modalidades de política de ação afirmativa dependem da definição que damos ao conceito. Se definida como toda medida que tem como objetivo a proteção ou promoção de grupos desprivilegiados, a ação afirmativa engloba um vasto cabedal de políticas, que vão de cotas e reservas de vagas em universidades, parlamentos e empregos públicos e privados a políticas especiais de proteção de áreas comunistárias e práticas culturais.
} 
promoção de membros de grupos historicamente discriminados. Entre as medidas, incluem-se cotas de representação política nas legislaturas estaduais e nacionais, cotas de contratação no serviço público e cotas nas instituições públicas de ensino superior.

Os atuais beneficiários das políticas de ação afirmativa na Índia são os Dalits, que receberam dos britânicos a denominação legal de Scheduled Castes (SCs) e representam 15\% da população; as tribos ou Scheduled Tribes (STs), grupos cujas formas de subsistência em áreas florestais vêm sendo crescentemente ameaçadas pela expansão demográfica e econômica dos outros indianos e constituem $7,5 \%$ da população do país; e as Other Backward Classes (OBCs), demais grupos de castas baixas, em especial Shudras, também considerados social e economicamente desprivilegiados e que representam 52\% dos indianos (Tummala, 1999). Mesmo muitas décadas depois da proibição legal da discriminação, a incidência da pobreza entre esses grupos é maior do que no restante da população, a mobilidade social ascendente é menor e os investimentos educacionais trazem menos retorno do que aquele obtido pelos demais indianos (Madheswaran; Attewell, 2007).

A história da ação afirmativa no Brasil é muito mais recente. Em 2001, o governo federal assinou a Declaração de Durban, se comprometendo a criar políticas afirmativas que visassem a combater a discriminação racial (Htun, 2001). Em sequência, o próprio governo federal começou a dar o exemplo, adotando medidas de discriminação positiva na composição de alguns dos seus quadros funcionais de alguns de seus Ministérios, como o do Desenvolvimento Agrário, da Justiça e das Relações Exteriores. Em 2003, a Lei Estadual no. 4.151 deu o pontapé inicial nas políticas de ação afirmativa no Brasil ao estabelecer cotas para pretos, pardos e alunos de escolas públicas nas universidades públicas do Rio de Janeiro, Uerj e Uenf. Ao longo dos anos subsequentes leis estaduais 
e resoluções de conselhos universitários disseminaram medidas similares em universidades estaduais por todo o país, ao passo que programas federais como o REUNI (Programa de Apoio a Planos de Reestruturação e Expansão das Universidades Federais) proporcionaram incentivos para que as instituições federais de nível superior adotassem essas políticas. Em 2012 foi finalmente sancionada a Lei 12.711, que tornou obrigatória a destinação de $50 \%$ das vagas nas IES federais para estudantes egressos de escolas públicas, com subcotas para pretos, pardos e indígenas. No Brasil, assim como na Índia, os grupos promovidos pela ação afirmativa são maioria na população. ${ }^{6}$ Somente pretos e pardos somam mais de $51 \%$ dos brasileiros, segundo o Censo 2010 do IBGE. ${ }^{7}$ Tamanha é a velocidade da expansão da ação afirmativa que publicar dados é contentar-se com a inevitabilidade de sua obsolescência: a cada ano mais iniciativas semeIhantes surgem no Congresso Nacional, nas assembleias estaduais e nas próprias universidades.

\section{O debate acadêmico e os argumentos contrários às ações afirmativas}

Pesquisas nacionais conduzidas no Brasil têm indicado que a opinião pública está dividida no que diz respeito às ações afirmativas (Datafolha, 2008). Um survey realizado em 2006 mostrou, por exemplo, que a maioria dos brasileiros é favorável a essas medidas - $65 \%$ a favor das cotas raciais e $87 \%$ das cotas sociais (Uol, 2006). No entanto, a cobertura dessas políticas pela mídia dá a falsa impressão de que posições contrárias

\footnotetext{
${ }^{6}$ Nos Estados Unidos, por exemplo, os negros perfazem somente 13,2 \% da população. Ver http://quickfacts.census.gov/qfd/states/00000.html.

${ }^{7}$ Fonte: http://www.ibge.gov.br/home/estatistica/populacao/censo2010/sinopse/sinopse_tab_ brasil_zip.shtm.
} 
superam as favoráveis, uma vez que os detratores das ações afirmativas ocupam mais espaço do que os seus defensores (Campos, Feres Jr. e Daflon, 2011). O mesmo pode ser dito a respeito da cobertura midiática das políticas de reserva na Índia: apesar de um grande apoio popular a essas medidas (Weisskopf, 2004; Bains, 1994), a cobertura da mídia apresenta um viés negativo muito forte (Rajalakshmi; Tripathi, 2008).

Nesse artigo, focalizamos os argumentos sustentados pelos membros das comunidades acadêmicas indiana e brasileira que se opõem às ações afirmativas. No caso do Brasil, utilizamos como fonte de dados o livro Divisões perigosas: políticas raciais no Brasil contemporâneo (Fry et al. 2007), editado por acadêmicos que desempenharam um papel de liderança na oposição às ações afirmativas no debate público. O livro é um compêndio de 50 textos, cuja maioria foi publicada em jornais e revistas, por um grande número de autores, a maioria deles acadêmicos. Embora não se possa afirmar que a amostra seja representativa do total de textos publicados contra as ações afirmativas no Brasil, trata-se de uma amostra selecionada pelos principais atores do debate. Alguns dos autores, assim como os editores do referido livro, desenvolveram previamente trabalhos acadêmicos sobre relações raciais no Brasil a partir de uma abordagem sociológica, histórica ou antropológica (Fry 1996, 2000, Maggie 1996, Maio 1997, Ventura Santos 1998, Pinto de Góes and Florentino 1995).

No caso da Índia, elaboramos uma lista de intelectuais que se opõem às políticas de reserva a partir de sugestões de nove acadêmicos indianos especializados no assunto ${ }^{8}$ e de referências bibliográficas reunidas em dois centros de pesquisa especializados em estudos de minorias ${ }^{9}$.

\footnotetext{
${ }^{8}$ Professores N Kumar, M Rehman, M F Hussain e M M Khan, da Jamia Millia Islamia University; professores K Chenoy, V Verma e A Singh, da Jawaharlal Nehru University; professor S Deshpande, da New Delhi University; e professora C D'Costa, do St. Xaviers College, Mumbai. ${ }^{9}$ Dr. K. R. Narayanan Centre for Dalit and Minorities Studies e Indian Institute of Dalit Studies.
} 
Os dois procedimentos resultaram em uma lista de 31 acadêmicos anti-reservacionistas cujos perfis profissionais se assemelham àqueles dos acadêmicos que lideram o movimento contra as ações afirmativas no Brasil: a maior parte deles construiu suas carreiras analisando a realidade das castas indianas (Omvedt, 2002: 414).

A tabela 1 agrupa os argumentos mais incidentes entre os acadêmicos indianos e brasileiros opositores das ações afirmativas de acordo com suas semelhanças temáticas e mostra sua correspondência no Brasil e na Índia.

\section{TABELA 1}

\begin{tabular}{|c|c|}
\hline BRASIL & ÍNDIA \\
\hline \multicolumn{2}{|l|}{ 1. Raça / Casta e Identidade Nacional } \\
\hline Racialização / Reificação das raças & Anti-secularismo / Reificação das castas \\
\hline Criação ou acirramento do conflito racial & Acirramento do conflito comunal \\
\hline Importação do modelo norte-americano & Legado do colonialismo britânico \\
\hline Crise da identidade nacional brasileira & Crise da identidade nacional indiana \\
\hline Imposição de uma identidade binária & Imposição de identidades rígidas \\
\hline \multicolumn{2}{|c|}{ 2. Cidadania e Estado } \\
\hline Violação da igualdade legal & Violação da igualdade legal \\
\hline Prejudicial ao mérito & Prejudicial ao mérito \\
\hline $\begin{array}{l}\text { Ruptura com a tradição republicana bra- } \\
\text { sileira }\end{array}$ & - \\
\hline Intervenção do Estado nas relações sociais & - \\
\hline \multicolumn{2}{|c|}{ 3. Procedimentos e Resultados } \\
\hline Ineficaz no combate às desigualdades & Ineficaz no combate às desigualdades \\
\hline Questão da vigência & Questão da vigência \\
\hline $\begin{array}{l}\text { Benefício da classe média negra e exclusão } \\
\text { dos brancos pobres }\end{array}$ & $\begin{array}{l}\text { Criação de uma "creamy-layer" e exclusão } \\
\text { dos pobres }^{1}\end{array}$ \\
\hline
\end{tabular}


continuação

\begin{tabular}{l|l}
\hline Estigmatização e vitimização dos beneficiários & Estigmatização e vitimização dos beneficiários \\
\hline Dificuldade de definição dos beneficiários & Dificuldade de definição dos beneficiários \\
\hline Exclusão de indígenas e pardos & $\begin{array}{l}\text { Exclusão de outros grupos discriminados, } \\
\text { como muçulmanos }\end{array}$ \\
\hline $\begin{array}{l}\text { Classe e não raça é a variável que explica a } \\
\text { desigualdade no Brasil }\end{array}$ & \\
\hline
\end{tabular}

\section{Raça/Casta e identidade nacional}

Neste grupo reunimos os argumentos que estabelecem uma relação entre raça ou casta e identidade nacional. No Brasil, argumenta-se que os formuladores das políticas de ação afirmativa no Brasil importaram dos Estados Unidos um sistema binário de identificação racial inadequado para lidar com a realidade da identidade racial e étnica do país, dividindo uma população mestiça entre negros e brancos (Benjamin, 2007; Pena, 2007; Magnoli, 2007; Goldenzon, 2007). As relações raciais nos Estados Unidos são retratadas por esses autores de forma bastante reducionista, como se elas se baseassem apenas na "one drop rule" ou regra de hipodescendência, isto é, na suposição de que no país o sujeito nascido como resultado de uma união interétnica ou inter-racial pertencesse sempre ao grupo étnico ou "racial" considerado biológica ou socialmente inferior. Alega-se então que essa forma de classificação não corresponde à realidade das identidades étnico-raciais no Brasil, marcadas pela plasticidade, flexibilidade e miscigenação (Fry et al, 2007).

Esse e outros argumentos apresentam analogias com aqueles que são mobilizados na Índia. A ideia de que a ação afirmativa vai "racializar" o Brasil, sustentada por boa parte dos acadêmicos, encontra correspon- 
dência na alegação muito recorrente entre antirreservacionistas indianos que esse tipo de política promove uma "antissecularização" do país, bem como uma reificação de categorias identitárias (Mitra, 1994; Bayly, 2001; Dhavan, 2008; Ranadive, 2002; Béteille, 2005). Note-se que o fato de o sistema de castas indiano gerir-se por rigorosas regras de endogamia não impede que lhe atribuam um caráter "maleável". Membros de castas mais elevadas, entre as quais se localizam muitos dos acadêmicos contrários às políticas de reserva, propalam a ideologia da "sanskritização" como uma via não conflituosa de mobilidade ascendente que seria preferível às políticas públicas que pretendem introduzir a possibilidade de ascensão individual. Trata-se de uma promessa de ascensão coletiva para aqueles pequenos grupos que reproduzirem os hábitos e rituais característicos das castas mais elevadas (Srinivas, 1969; Panandiker, 1997).

Segundo alguns intelectuais brasileiros, pelo simples fato de basear-se em categorias raciais para definir os seus beneficiários, a ação afirmativa vai elevar a "raça" a uma categoria oficial, reconhecida pelo Estado, e, por conseguinte, promover o racismo (Benjamin, 2007; Schwartzman, 2007; Zahur, 2007). Os críticos indianos das ações afirmativas, por sua vez, alegam que a utilização das castas como critério de distribuição de benefícios representa um passo atrás nas metas de secularização da Índia. Como as castas fazem parte da religião Hindu, eles entendem que qualquer movimento de combate ao casteísmo que lance mão da noção de casta apenas logrará promover o que se propõe a extinguir, isto é, o próprio sistema de castas e a supremacia Hindu, ou a "saffronização" da Índia (Panandiker, 1997; Kumar, 1992; Bayly, 2001).

A ideia de que a ação afirmativa ameaça a identidade nacional é central nesse conjunto de argumentos. No caso do Brasil, apela-se para a suposta tradição nacional de mestiçagem como um valor que integra as pessoas e harmoniza as diferenças, produzindo uma sociedade sem conflito racial, discriminação ou racismo (Zahur, 2007; Benjamin, 2007; 
Pinto de Góes, 2007; Vainfas, 2007). Essa ideologia disseminou-se no senso comum do brasileiro, bem como tornou-se um discurso semi-oficial sobre a identidade nacional do país, em oposição às interpretações anteriores que explicavam o atraso do país como resultado da miscigenação (Skidmore, 1976).

Contudo, com a redemocratização do Brasil a partir dos anos 1980, os movimentos sociais e forças políticas progressistas começaram a questionar essa ideologia. Análises sociológicas baseadas em dados socioeconômicos nacionais, feitas por Carlos Hasenbalg e Nelson do Valle Silva, revelaram uma grande distância entre brancos e não brancos (pretos e pardos) (Hasenbalg, 1992; Hasenbalg, 1979; Silva, 1983). Consequentemente, o debate sobre a ação afirmativa no Brasil é também um debate sobre as diferentes maneiras de conceber a identidade nacional brasileira: uma maneira mais antiga, associada a mitos fundacionais de unidade baseados nas supostas virtudes da mistura "racial", e uma nova, baseada nas noções democráticas de igualdade de oportunidades e direitos.

Na Índia, o valor sendo defendido é a ideia de "unidade na diversidade" (Panandiker, 1997) em um país que se percebe como essencialmente tolerante com relação às diferenças e culturas que o compõem. Embora tenha recentemente revisto suas posições, o intelectual indiano Amartya Sen argumentou por décadas que as políticas de ação afirmativa baseadas em pertencimento a grupos focalizados enfraqueciam a luta pela igualdade, que na sua visão requereria uma abordagem universalista (Sen, 2001). As políticas de reserva são, portanto, frequentemente encaradas como uma ameaça para o projeto de nation-building indiano e para a própria nação em si, que pode fragmentar-se em vista do fortalecimento das identidades comunitárias (Panandiker, 1997; Sen, 2005; Bayly, 2001, Kumar, 1992).

Algumas interpretações a respeito dos processos de construção nacional da Índia e do Brasil guardam semelhanças entre si. Alguns acadê- 
micos indianos sugerem que a divisão hierárquica da sociedade indiana foi um aspecto positivo da invasão ariana-brâmane em 1500 a.C. Segundo eles, a divisão da sociedade em castas permitiu que os conquistadores assimilassem as populações autóctones em ocupações subalternas, poupando-as assim da aniquilação física (Nanda, 2007). De forma similar, alguns historiadores e cientistas sociais brasileiros alegam que o processo de construção da sociedade foi caracterizado pela plasticidade e tolerância dos colonizadores portugueses, os quais, apesar de terem escravizado os africanos e os povos indígenas, teriam construído uma sociedade harmônica e multicultural, na qual as "três raças" foram integradas e se misturaram nos planos biológico e cultural (Pinto de Góes, 2007).

Desse modo, tanto na Índia como no Brasil, a ação afirmativa é culpada por supostamente provocar conflito e violência por reforçar as divisões em sociedades pretensamente harmônicas. No caso da Índia as reservas são responsabilizadas por produzir episódios violentos como o caso dos tumultos de 1981 em Gujarat e os protestos nacionais de 1990, durante os quais jovens estudantes brâmanes cometeram suicídio por autoimolação. Ambos os episódios foram motivados pelo anúncio da ampliação das reservas pelo governo (Wood, 1987; Prakash, 1997).

No Brasil, por outro lado, considerando o fato de que as ações afirmativas são relativamente recentes se comparadas à Índia ou mesmo aos Estados Unidos, seus antagonistas tendem a apresentar esse argumento como um prognóstico. Em outras palavras, o argumento não se baseia em eventos, dados empíricos ou na experiência das instituições universitárias com os programas de ação afirmativa, mas em predições acerca do conflito social, violência e barbárie causados pelas cotas raciais (Lamounier, 2007; Benjamin, 2007; Schwartzman, 2007; Zahur, 2007).

Frequentemente membros das academias brasileira e indiana evocam as origens das políticas de ação afirmativa a fim de desquali- 
ficá-las e retratá-las como uma imposição, um elemento exógeno ao contexto nacional em questão. No Brasil é comum a alegação de que a ação afirmativa é não apenas uma importação dos Estados Unidos, mas também parte do projeto imperialista norte-americano de "racializar" o Brasil (Schwartzman, 2007, Carvalho, 2007; Magnoli, 2007). O argumento do "imperialismo" tem um paralelo intrigante na Índia, onde se diz que essa política constitui parte de um legado maléfico deixado pelos colonizadores britânicos.

De fato, até hoje as políticas de reserva são associadas ao colonialismo inglês devido ao fato de os primeiros programas terem sido implementados durante o Raj Britânico (Dhavan, 2008; Ranadive, 2002; Panandiker, 1997; Bayly, 2001; Béteille, 2008). Os novos postos oferecidos pela administração britânica a partir dos anos 1860 levaram a algumas consequências não previstas, uma vez que pessoas de castas baixas começaram a demandar uma distribuição de oportunidades mais equitativa. Elas se ressentiram do fato de que, apesar de representarem não mais que 3 por cento da população, os brâmanes monopolizaram inteiramente os empregos disponíveis para os indianos na administração colonial (Weisskopf, 2004). Os movimentos anti-brâmanes pressionaram então pela criação de reservas no serviço público e nas instituições educacionais e essas demandas foram bem recebidas pelos ingleses, uma vez que a negociação com líderes políticos das castas baixas poderia dissuadir porções significativas da população de se engajar na luta pela independência liderada por grupos de castas altas (Mcmillan, 2005).

A linha argumentativa que desqualifica as políticas de reserva ao apresentar um argumento histórico costuma tomar de empréstimo a linguagem dos estudos pós-coloniais: alega-se que os colonizadores da Índia, no emprego de uma estratégia de "dividir para conquistar", reforçaram ou mesmo "inventaram" o sistema de castas, tanto por terem conduzido o 
primeiro censo populacional como por terem criado as primeiras políticas em benefício de grupos desprivilegiados (Shourie, 2006). Contudo, essa interpretação histórica está longe de ser consensual. Alguns autores sustentam que embora haja alguma verdade na alegação de que as estatísticas oficiais produzidas pelos britânicos não foram capazes de capturar as dinâmicas do sistema de castas, simplificando e enrijecendo determinadas divisões, os colonizadores não podem ser acusados de "forjar" o casteísmo na Índia. Assim, culpar os ingleses por tornar o sistema mais rígido não é uma desculpa válida para negar direitos básicos a determinados grupos desde tempos pré-coloniais (Gavaskar, 2007; Sheth, 2002).

Críticos brasileiros e indianos das ações afirmativas extraem elementos de tradições culturais, sociais, políticas e históricas bem diferentes para formular esse grupo de argumentos. No caso brasileiro, alude-se ao problema do racismo, à reificação de categorias raciais e à suposta importação de modelos e categorias norte-americanas em virtude de "imperialismo acadêmico". No indiano, denunciam-se as reservas como um mecanismo de quebra com a laicidade do Estado, em virtude do uso de categorias do sistema religioso de castas por essas políticas públicas, bem como se argumenta que elas são um legado do colonialismo britânico. Não obstante, a estrutura desses argumentos é bastante similar. Eles consistem em tentativas de desqualificar as políticas de ação afirmativa ao se evocar o perigo de submissão a poderes externos - o que representaria uma verdadeira ameaça à identidade nacional.

\section{Cidadania e Estado}

O segundo conjunto de argumentos a que denominamos "Cidadania e Estado" tem como temas centrais as questões da igualdade formal 
e do mérito, princípios que são conjurados com o fim de questionar a compatibilidade da ação afirmativa com princípios democráticos. Os argumentos agrupados nesse grupo temático se articulam em torno da ideia de que a igualdade legal formal e o mérito devem ser os dois únicos princípios legítimos de regulação do acesso a posições sociais de prestígio, sob a alegação de que somente eles são capazes de combater efetivamente o estabelecimento de privilégios (Kumar, 1992; Béteille, 2008; Deshpande, 2006; Lustosa, 2007; Fry, 2007; Goldenzon, 2007; Pinto de Góes, 2007).

De acordo com Thomas Weisskopf (2004), o argumento de que as políticas de reserva violam os princípios do mérito, da competição aberta e da eficiência são os mais recorrentes no contexto indiano. Em nome do crescimento econômico e da excelência acadêmica, alega-se que a adoção de cotas no serviço público e na educação superior resulta na seleção de indivíduos menos qualificados e capazes, o que por seu turno seria a causa por trás da má qualidade da educação e dos serviços no país (Kumar, 1992; Béteille, 2005; Béteille, 2008; Deshpande, 2006). Tais argumentos são também muito incidentes no contexto brasileiro, onde se alega que em um curto período de tempo as cotas serão capazes de diminuir a qualidade da educação superior, bem como reduzir o capital humano do país (Lustosa, 2007; Goldenzon, 2007; Fry, 2007).

Os procedimentos adotados pelas universidades brasileira e indiana para a seleção dos candidatos aos cursos superiores são muito similares. Os candidatos fazem exames admissionais e são ranqueados conforme suas notas. Pouca ou nenhuma importância é dada à sua trajetória acadêmica ou a outros critérios. Por essa razão, acredita-se que a seleção ao ensino superior é conduzida exclusivamente sob critérios neutros e meritocráticos. Quem se opõe a esse tipo de argumento alega que as profundas diferenças entre as escolas públicas e privadas em ambos os países, assim como a existência de cursos preparatórios caros e extremamente elitizados concebidos para aumentar a competitividade dos estudantes 
mais abastados é responsável pela reprodução das desigualdades na educação superior e pela distorção do sistema de mérito (Grewal, 2006). Em consequência disso, apenas as ações afirmativas seriam capazes de interferir nesse ciclo vicioso.

\section{Procedimentos e Resultados}

Esse último conjunto se caracteriza por reunir argumentos de ordem mais técnica, que fazem predições ou diagnósticos acerca dos supostos resultados e procedimentos insatisfatórios da ação afirmativa. De acordo com essa linha argumentativa, é difícil estabelecer um limite para tais políticas, isto é, uma vez que elas são implementadas, seria praticamente impossível interrompê-las. De fato, as políticas de reserva estão em vigência na Índia há décadas e nenhuma delas foi suspensa até o presente. Alguns acadêmicos creditam essa situação ao fato de que nenhum partido político está interessado em perder o apoio dos beneficiários e, portanto, ninguém está disposto a propor sua extinção (Parikh, 1997; Kumar, 1992). No Brasil, talvez em razão da experiência relativamente curta com tais políticas, essa questão não se transpôs completamente para a política partidária, ainda que alguns dos seus opositores tentem atribuí-las a um suposto radicalismo político dos presidentes Lula e Dilma e do seu Partido dos Trabalhadores (PT), e políticos de destaque do PSDB e do DEM tenham se tornado campeões da luta contra as cotas. ${ }^{10}$

$\mathrm{O}$ argumento segundo o qual a ação afirmativa é ineficiente em diminuir desigualdades foi utilizado tanto na Índia como no Brasil (Kijima, 2006; Bains, 1994; Shah, 2002; Ranadive, 2002; Béteille, 2008;

\footnotetext{
${ }^{10}$ Entre os políticos desses partidos que publicamente militaram contra a ação afirmativa racial temos o finado Paulo Renato Costa, ex-Ministro da Educação do Governo Fernando Henrique Cardoso e, depois, deputado federal pelo PSDB, o senador Demóstenes Torres, (DEM), principal articulador da ADF contra a ação afirmativa julgada improcedente pelo Supremo Tribunal Federal em 2012, e Aloysio Nunes (PSDB), senador que até hoje faz oposição às políticas de igualdade racial.
} 
Schwartzman, 2007; Fry, 2007; Lamounier, 2007; Chor Maio e Santos, 2007). Essa crítica parece se basear em uma interpretação da ação afirmativa como uma política encarregada de reduzir todas as formas de desigualdade socioeconômica - uma visão contestada por autores que alegam que tais políticas têm como objetivo apenas possibilitar o acesso de membros de grupos desprivilegiados a posições de prestígio em que eles se encontram sub-representados e não têm a capacidade nem o propósito de resolver a desigualdade como um todo (Hasan, 2009; Weisskopf, 2004). Outra crítica comum à ação afirmativa em ambos os países reside em alegar que ela beneficia apenas os membros mais bem-sucedidos dos grupos desprivilegiados, isto, é as classes médias ou, na terminologia indiana, a "creamy layer". Na conclusão discutiremos esse argumento e as respostas a ele mais detidamente.

Finalmente, os dois últimos argumentos desse grupo temático consistem na alegação que a ação afirmativa promoverá a exclusão dos indígenas e dos indivíduos pardos (Schwartzman, 2007; Carvalho, 2007; Magnoli, 2007) e que dadas a suposta plasticidade e fluidez das relações raciais na sociedade brasileira é difícil obter uma definição precisa dos beneficiários com base em pertença "racial" (Benjamin, 2007; Pena, 2007; Florentino, 2007). Analogamente na Índia é possível encontrar o argumento de que as políticas de reserva promovem a exclusão de outros grupos discriminados, tais como os muçulmanos, por exemplo (Wright, 1997; Bayly, 2001), ou ainda que é difícil determinar quem deve se beneficiar dessas medidas (Dhavan, 2008; Panandiker, 1997; Chitnis, 1997; Prakash, 1997).

Políticas de ação afirmativa para indígenas nas universidades públicas são hoje tão numerosas como aquelas destinadas aos negros e são mais comumente encontradas em universidades estaduais situadas em regiões com populações indígenas mais numerosas (GEMAA, 2008). Ademais, a Lei 12.711/2012, que estabeleceu a obrigatoriedade da 
adoção de cotas nas IES federais, colocou os indígenas ao lado dos pretos e pardos como beneficiários das ações afirmativas. ${ }^{11}$ No que tange aos pardos, de fato é possível perceber que em muitas IES estaduais esse grupo com frequência não é beneficiado nominalmente, mas subsumido ao grupo dos "negros". Assim, acaba-se por exigir que os pardos identifiquem-se como negros para poder concorrer às cotas, algo que não é feito usualmente pelos brasileiros nas interações cotidianas (Osório 2003). Contudo, vale lembrar que a lei federal de cotas define os pardos explicitamente como alvos das políticas, o que de certo modo contribui para legitimá-los como beneficiários.

Por outro lado, a alegação de que não é possível definir as pessoas em termos de cor no Brasil contradiz um grande número de análises e evidências produzidas por sociólogos e antropólogos no país. Diversas pesquisas revelaram a existência de mecanismos de discriminação racial e da operacionalidade da raça como critério de distinção entre as pessoas (Guimarães 1999, 2002). Alguns trabalhos que empregaram metodologia semi-experimental mostraram até mesmo a operação de categorias de classificação racial (Osório, 2003). Além disso, análises sociológicas de bases de dados de amplitude nacional mostraram consistentemente a persistência da raça como um fator de produção de desigualdades (Marcelo Paixão et al. 2010). Mesmo quando a variável "renda" é controlada,

${ }^{11} \mathrm{O}$ desenho das políticas de cotas adotadas pelas universidades federais sob a Lei 12.711 pode variar bastante nos detalhes, ainda que o montante das reservas tem que ser o mesmo em todas as unidades. Os critérios de identificação dos beneficiários (indígenas, pretos e pardos) diferem. A maioria das instituições usa somente autodeclaração racial, mas algumas utilizam-se também de análises de fotos ou entrevistas. A maneira como essa declaração é feita também pode variar. Para os indígenas, em muitos casos a autodeclaração basta; em outros, como na UFRGS, solicita-se a comprovação de um cacique para atestar identidade indígena. Por exemplo, os critérios da UFRGS beneficiam indígenas que moram em aldeias enquanto os indígenas que moram nas cidades - os que supostamente estariam mais capacitados para cursar a universidade - são impedidos de gozar do benefício. 
persistem diferenças significativas entre brancos e não brancos (pretos e pardos) em termos de desempenho escolar, evasão e mobilidade social (Hasenbalg, 1979; Jaccoud; Beghin, 2002; Hasenbalg; Silva, 2003).

$\mathrm{Na}$ Índia a definição dos beneficiários não suscita grande controvérsia quando se trata das Scheduled Castes e Scheduled Tribes, e os relatórios produzidos por comissões públicas para recensear essas populações têm sido aceitos pelos indianos de modo geral. A controvérsia reside na classificação das Other Backward Classes (Dhavan, 2008; Panandiker, 1997; Prakash, 1997; Chitnis, 1997; Kumar, 1992), um grupo que carece de um marcador cultural, econômico e geográfico específico (Prakash, 1997) e apresenta grande heterogeneidade, além de não possuir um histórico de mobilização política e identitária (Shah, 2002). A imprecisão da definição desse grupo na Constituição Indiana e a adoção de definições nativas gerou um resultado inesperado: hoje há cerca de quatro mil jatis ${ }^{12}$ agrupadas sob essa categoria. Ainda assim, muitos acadêmicos defendem inclusão das OBCs nas políticas de reserva para a educação superior. Um survey urbano conduzido entre 1999 e 2000 pela National Sample Survey Organization demonstrou que embora pessoas de castas altas representem $37 \%$ da população urbana, eles representam $65 \%$ dos portadores de diploma superior. Em contrapartida, não apenas as Scheduled Castes, Scheduled Tribes mas também as Other Backward Classes estão sub-representadas entre a população urbana com educação superior (Deshpande, 2006).

Além da questão de classificar as OBCs, aponta-se também como um problema na Índia que as reservas deixam de fora grupos como os muçulmanos e Dalits cristãos, e que esses precisam então disputar recursos

\footnotetext{
${ }^{12}$ Termo genérico usado para denominar clãs, tribos, comunidades e religiões na Índia, que geralmente são associadas a funções sociais específicas ou ofícios. O sobrenome de um indiano geralmente faz referência a seu jati (Dirks 2001).
} 
e oportunidades ainda mais escassas. Os muçulmanos representam 13\% da população e sua condição socioeconômica indica que eles também se qualificam para políticas de ação afirmativa. Dalits convertidos ao cristianismo, por sua vez, não escapam do estigma social associado à sua condição de párias, mas, ao abraçar outra fé religiosa que não a Hindu, perdem seu direito às reservas na educação, no emprego público e na representação política. Zoya Hasan (2009) sugere que a relutância do Partido do Congresso em insistir na expansão da ação afirmativa para esses dois grupos representa uma concessão à direita religiosa e aos supremacistas hindus, que não desejam ampliar os benefícios a outras minorias religiosas.

\section{Três teses reacionárias}

Em A retórica da intransigência Albert Hirschman (1992) estudou os argumentos utilizados por intelectuais que se opuseram às políticas progressistas em três momentos históricos distintos, os quais ele denominou "ondas reacionárias"13. Cada uma dessas ondas se sucedeu a uma grande conquista na institucionalização da cidadania no Ocidente: a conquista dos direitos civis, a extensão de direitos políticos como produto da luta histórica pelo sufrágio universal, e a criação de direitos sociais sob o Estado de Bem-Estar social. Hirschman encontrou algumas regularidades nos argumentos daqueles que se opuseram a esses movimentos históricos, os quais ele denominou "três grandes teses reacionárias": perversidade, futilidade e ameaça. Propomos que os argumentos que encontramos no

\footnotetext{
${ }^{13}$ Hirschman entende a retórica como uma ação social proposital, seguindo o conceito de Merton. Ou seja, o autor da ação está consciente de seus propósitos mas não pode, por outro lado, prever todas as suas consequências. Na prática, Hirschman iguala a retórica à estratégia argumentativa empregada por um agente para se vencer um debate público. Seu foco é no aspecto semântico da retórica, daí a tipologia tripartite ser determinada a partir da classificação dos significados dos argumentos (Hirschman 1989, 293).
} 
debate acerca das ações afirmativas no Brasil e na Índia se encaixam com perfeição na tipologia proposta por Hirschman.

Aqueles que empregam a tese da perversidade sustentam que uma determinada medida desenvolvida para resolver um problema social particular apenas contribuirá para exacerbar esse mesmo problema que se propõe a mitigar. Aqueles que utilizam a retórica da futilidade, por sua vez, alegam que medidas progressistas são inócuas, isto é, não terão impacto significativo. Finalmente, aqueles que adotam a retórica da ameaça asseveram que os custos de implementar uma determinada política excedem seus potenciais benefícios ou, alternativamente, que a adoção de uma política pública põe em risco importantes conquistas obtidas anteriormente em nome de ganhos futuros incertos.

Os argumentos do primeiro grupo temático que apresentamos, "Raça/Casta e identidade nacional", podem ser enquadrados na tese da perversidade de Hirschman. De acordo com esses argumentos, as ações afirmativas, dirigidas à promoção de grupos marginalizados, produzirão o efeito inverso, isto é, o acirramento da marginalização em virtude do aumento do racismo, casteísmo, sectarismo e violência. A natureza epistêmica desses argumentos é eminentemente sociológica e antropológica e aqueles que os sustentam frequentemente o fazem com base em sua autoridade como cientistas sociais a fim de aumentar sua credibilidade.

A estratégia retórica de enfatizar a excepcionalidade nacional da Índia e do Brasil é um elemento fundamental na elaboração desses argumentos, visto que se rejeita a ação afirmativa com o pretexto de se impedir que elas produzam efeitos negativos não intencionais em sociedades com trajetórias particulares. Em ambos os países, as ações afirmativas são culpadas por tornar rígidos sistemas de estratificação social supostamente flexíveis e maleáveis. No caso do Brasil, diz-se que a ação afirmativa acirra ou mesmo cria divisões e conflitos raciais. Na Índia, as 
políticas de reserva são culpadas por episódios de violência casteísta que ocorreram nas últimas décadas.

O segundo grupo temático, denominado "Cidadania e Estado" pode ser associado à tese da ameaça. De acordo com ele, as ações afirmativas ferem o princípio do mérito e da igualdade formal e universal, duas grandes conquistas das sociedades modernas. A estratégia retórica empregada consiste em buscar demonstrar que os novos ganhos em termos de justiça social são incompatíveis com os anteriores. Em certo sentido essa tese é mais sutil do que a do efeito perverso, uma vez que aceita que as novas políticas podem trazer benefícios apenas para em sequência rejeitá-las sob a alegação de que seus custos vão superar esses ganhos.

Finalmente, os argumentos relativos ao terceiro grupo temático, "Procedimentos e resultados", aproximam-se da tese da futilidade, pois todos eles residem em alegar que as políticas de ação afirmativa falharão tanto no que se refere à sua implementação como à produção dos objetivos almejados. Defender que essas políticas atingirão apenas as classes médias e não terão qualquer impacto sobre as desigualdades sociais equivale a dizer que elas não produzirão efeito algum sobre o atual estado de coisas. $\mathrm{O}$ argumento de que é impossível distinguir negros de brancos ou identificar os beneficiários indianos também procura corroborar a ideia de que as políticas serão ineficientes, se não injustas.

\section{Considerações finais}

Há ainda carência de estudos no Brasil que avaliem se as políticas de discriminação positiva agravam o conflito racial, mas a atitude geral dos pretos e pardos brasileiros depois de mais de uma década de ações afirmativas não demonstra qualquer inclinação para atos de violência contra os brancos. No caso da Índia, há diferenças regionais não negligenciáveis 
a esse respeito. Enquanto no Sul não há registro de manifestações violentas em favor ou contra as políticas de reserva (Kumar, 1992), há notícia de alguns incidentes sérios envolvendo protestos contra as ações afirmativas no Norte. O que não causa surpresa é o fato de esses casos de reação violenta às ações afirmativas terem sido iniciados por grupos que historicamente se vincularam ao linchamento de Dalits e outras formas de violência, desde os tempos pré-coloniais até o presente (Costa; Saxena, 2007).

Com relação à ideia de que a ação afirmativa viola o princípio do mérito, vale notar o contra-argumento do líder político dos Dalits, B.R. Ambedkar (2002), de que eram precisamente as políticas de reserva os instrumentos que introduziriam verdadeiro mérito na sociedade indiana. Ele criticou ainda a ordem social Hindu em virtude dos princípios hierárquicos que regulam as relações sociais e que são transpostos para a economia, além de alegar que os hindus se tornaram incapazes de valorizar e recompensar os méritos individuais sem interferência do preconceito casteísta. Um argumento similar foi empregado no Brasil, onde a ação afirmativa é vista por seus defensores como um instrumento que introduz o reconhecimento do mérito em um país onde o preconceito e a discriminação afetam a maneira como as chances e oportunidades são distribuídas no mercado de trabalho e no sistema educacional (Guimarães, 2000).

A acusação de que as políticas de reserva na Índia beneficiam na prática os membros menos desprivilegiados dos grupos visados pode ter fundamento nos casos das Scheduled Castes e Scheduled Tribes, mas não no caso das OBCs, uma vez que a Suprema Corte do país excluiu a "creamy layer" desse grupo do benefício das reservas. Nos casos das Scheduled Castes e Scheduled Tribes, as políticas podem de fato ser "culpadas" pela promoção das seções menos desprivilegiadas de tais grupos, mas apenas porque as próprias medidas foram concebidas para esse propósito. Juízes e legisladores indianos entendem que as reservas devem mirar todos os 
membros das Scheduled Castes e Scheduled Tribes, precisamente por causa da natureza da sua desvantagem. Alega-se que o preconceito de casta na Índia é tão acentuado que mesmo os Dalits ou membros de tribos que conseguem obter melhores condições socioeconômicas continuam a enfrentar formas severas de discriminação (Nesiah, 1999).

No Brasil, essa acusação não encontra suporte empírico, pois a maior parte das universidades públicas estaduais exigem dos candidatos às cotas raciais que sejam egressos do sistema público de ensino - um critério que funciona no país como proxy de baixa renda - para que possam se qualificar para o benefício (GEMAA, 2008). No caso das universidades públicas federais, a Lei 12.711/2012 estipulou um duplo critério: todas as vagas destinadas a pretos, pardos e indígenas vêm com a exigência de que eles procedam de escolas públicas, e a metade delas é reservada para aqueles que possuam renda familiar per capita abaixo de 1,5 salário mínimo. Ademais, a alegação de que tais políticas excluem os brancos pobres não possui fundamento por duas razões: primeiro, porque no caso dos cursos universitários mais competitivos aqueles que são excluídos em razão do sistema de cotas são normalmente estudantes brancos de classe média e elite; e segundo porque foi apenas como resultado da pressão dos movimentos sociais por políticas de ação afirmativa que as cotas para estudantes de escolas públicas - geralmente muito mais pobres do que os estudantes de instituições privadas e, dentre eles, muitos brancos pobres - foram criadas.

Além disso, é de comum conhecimento que o acesso à educação superior demanda um acúmulo mínimo de recursos econômicos, culturais e políticos. É irrealista supor que os mais pobres entre os pobres terão condições de alcançar o benefício das ações afirmativas. O uso indiscriminado do argumento da creamy layer aumenta os riscos de se "desqualificar aqueles segmentos das castas e comunidades socialmente desprivilegiadas que têm boas chances de sucesso" (Deshpande, 2006: 2441). 
É cedo para avaliar se as ações afirmativas falham em reduzir as desigualdades no Brasil, uma vez que essas políticas estão em vigência há pouco mais de uma década. No caso da Índia, após seis décadas de reservas, os resultados já estão visíveis. De fato, dados produzidos pelo relatório do governo indiano de 2006 "Status Social, Econômico e Educacional da Comunidade Muçulmana" indica que a proporção geral de portadores de diploma superior na Índia aumentou entre a década de 1970 e 2000 e as taxas de graduação de Scheduled Castes e Scheduled Tribes também apresentaram uma tendência de crescimento, aumentando de 0,9\% para $8 \%$ da sua população. O mesmo relatório demonstra que um grupo discriminado que não está sob proteção das ações afirmativas, os muçulmanos, teve sua participação na educação superior reduzida ao longo dos anos (Hasan, 2009).

Como argumentou Hirschman, o problema das três estratégias retóricas que localizamos na argumentação pública contra as ações afirmativas não é o conteúdo substantivo dos argumentos, mas sua natureza reacionária, no verdadeiro sentido da palavra. Seu objetivo é obstruir ações que trarão mudanças sociais por meio de especulações baseadas em parcas evidências empíricas. De um ponto de vista politicamente progressista, uma abordagem pragmática em relação à elaboração e implementação de políticas públicas é uma opção muito mais razoável. Nenhuma política é perfeita, mas todas elas podem ser aprimoradas através de um trabalho contínuo de avaliação e reformulação das suas premissas e métodos. Esse parece ser o caso da ação afirmativa tanto na Índia como no Brasil. Se as evidências apontam para a necessidade de reelaborar alguns métodos e procedimentos, os resultados produzidos até o momento não dão sustentação aos apelos para cancelar essas políticas, a despeito da contínua oposição e militância de alguns acadêmicos e publicistas. 
João Feres Jr é PhD em Ciência Política pela Universidade da cidade de Nova York e Professor de Ciência Política do Instituto de Estudos Sociais e Políticos (IESP), da UERJ. Coordena o GEMAA - Grupo de Estudos Multidisciplinares da Ação Afirmativa e o LEMEP - Laboratório de Estudos de Mídia e Esfera Pública. $\triangle$ jiferes@iesp.uerj.br

Verônica Toste Daflon é Doutora em Sociologia pelo Instituto de Estudos Sociais e Políticos (IESP-Uerj). Pesquisadora associada do Núcleo Interdisciplinar de Estudos Sobre a Desigualdade (NIED, IFCS-UFRJ).\veronicatoste@gmail.com

\section{Referências}

1. AMBEDKAR, B.R. Caste in India. In Shah, G. (org.) Caste and Democratic Politics in India. New Delhi: Permanent Black, pp. 83-107, 2002.

2. ARNOVE, R.F. Philanthropy and Cultural Imperialism: The Foundations at Home and Abroad. Bloomington: Indiana University Press, 1982.

3. BAINS, R.S. Reservation Policy and Anti-reservationists. New Delhi: B.R. Publishing Corporation, 1994.

4. BAYLY, S. Caste, Society and Politics in India from the Eighteenth Century to The Modern Age. Cambridge: Cambridge University Press, 2001.

5. BENJAMIN, C. Tortuosos caminhos. In: FRY, P et al (Orgs). Divisões Perigosas: Políticas Raciais no Brasil Contemporâneo. Rio de Janeiro: Civilização Brasileira, pp. 27-34, 2007.

6. BERGER, M.T. 'Civilising the South: The US Rise to Hegemony in the Americas and the Roots of 'Latin American Studies' 1898-1945'. Bulletin of Latin American Research, 12(1), pp. 1-48, 1993.

7. BÉTEILLE, A. Universities as public institutions. Economic and Political Weekly. July 30, pp. 3377-3381, 2005.

8. BÉTEILLE, A. Access to education. Economic and Political Weekly. May, 17, pp. 40-48, 2008.

9. CAHN, Steven M. The affirmative action debate. New York: Routledge, 2002.

10. CAHN, Steven M. (2002) The affirmative action debate. New York: Routledge, 2002. 
11. CARVAlHO, J.M. Genocídio racial estatístico. In: FRY, P. et al (Orgs). Divisões Perigosas: Políticas Raciais no Brasil Contemporâneo. Rio de Janeiro: Editora Civilização Brasileira, pp. 111-116, 2007.

12. COSTA, F; SAXENA, S. A Índia que os Indianos veem. Revista Inteligência. April-may-june, pp. 106-124, 2007.

13. CHITNIS, S. Definition of the Terms Scheduled Castes and Scheduled Tribes: a Crisis of Ambivalence. In: PANANDIKER, V.A.P. The Politics of Backwardness Reservation Policy in India. New Delhi: Konark Publishers PVT LTD, pp. 88, 1997.

14. DATAFOLHA. Opinião Pública: Cotas. Disponível em: http://datafolha.folha.uol.com.br/po/ver_po.php?session=781. Acesso em 27/11/2008

15. DESHPANDE, J.V. Towards a knowledge-based society'. In: Economic and Political Weekly. September 16, pp. 3933-3936, 2006.

16. DHAVAN, R. Reserved! How Parliament debated reservations 1995-2007. New Delhi: Rupa \& Co, 2008.

17. DIRKS, Nicholas B. Castes of mind: colonialism and the making of modern India. Princeton, N.J.: Princeton University Press, 2001.

18. FERES JR, J.; ZONINSEIN, J. Introdução: ação afirmativa e desenvolvimento. In: FERES JR, J.; ZONINSEIN, J. (Orgs.) Ação afirmativa e universidade: experiências nacionais comparadas. Brasília: Editora UnB, pp. 9-45, 2006.

19. FLORENTINO, M.G. Da atualidade de Gilberto Freyre. In: FRY, P. et al (Orgs). Divisões Perigosas: Políticas Raciais no Brasil Contemporâneo. Rio de Janeiro: Editora Civilização Brasileira, pp. 89-94, 2007.

20. FRY, P. O que a Cinderela Negra tem a dizer sobre Política racial no Brasil. Revista da USP (28), pp. 13-34, 1996.

21. FRY, P. Politics, nationality, and the meanings of 'race' in Brazil. Journal of the American Academy of Arts and Sciences - DAEDALUS, 129(2), pp. 83-118, 2000.

22. FRY, P. Introduzindo o racismo. In FRY, P. et al (Orgs). Divisões Perigosas: Políticas Raciais no Brasil Contemporâneo. Rio de Janeiro: Editora Civilização Brasileira, pp. 155-160, 2007.

23. FRY, P. et al. (Orgs). Divisões perigosas: políticas raciais no Brasil contemporâneo. Rio de Janeiro: Civilização Brasileira, 2007.

24. GAVASKAR, M. Colonialism within Colonialism: Phule's Critique of Brahmin Power. In: MICHAEL, S.M. (org) Dalit in Modern India. New Delhi: Sage Publications. P.91-107, 2007. 
25. GOLDENZON, S. Eles deveriam pedir desculpas, de joelhos. In: FRY, P. et al (Orgs). Divisões Perigosas: Políticas Raciais no Brasil Contemporâneo. Rio de Janeiro: Civilização Brasileira, pp. 149-154, 2007.

26. GUIMARÃES, A.S. Racismo e antirracismo no Brasil. São Paulo: Fundação de Apoio à Universidade de São Paulo: Editora 34, 1999.

27. GUIMARÃES, A.S. Insulto racial: as ofensas verbais registradas em queixas de discriminação. Estudos Afro-Asiáticos, Rio de Janeiro, (38), dez., 2000.

28. GUIMARÃES, A.S. Classes, raças e democracia. São Paulo: UFSP / Editora 34, 2002.

29. GREWAL, J S. Morality and the reservation issue. Economic and Political Weekly. Sep. 30. p. 4114-4116, 2006.

30. HASAN, Z. Politics of Inclusion Castes, Minorities, and Affirmative Action. New Delhi: Oxford University Press, 2009.

31. HASENBALG, C. Discriminação e desigualdades raciais no Brasil. Rio de Janeiro: Graal, 1979.

32. HASENBALG, C. Relações Raciais no Brasil Contemporâneo. Rio de Janeiro: Editora Rio Fundo/luperj, 1992.

33. HASENBALG, C.; SILVA, N.D.V. Origens e destinos: desigualdade social ao longo da vida. Rio de Janeiro: Topbooksed, 2003.

34. HIRSCHMAN, A.O. A retórica da intransigência: perversidade, futilidade, ameaça. São Paulo: Companhia das Letras, 1992.

35. HIRSCHMAN, A.O. Two Hundred Years of Reactionary Rhetoric: The Case of the Perverse Effect. Vol. 10, The Tanner Lectures in Human Values. Salt Lake City: University of Utah Press, 1989.

36. HTUN, M.A Política de Cotas na América Latina. Revista Estudos Feministas, $9(1), 2001$.

37. JACCOUD, L.; BEGHIN, N. Desigualdades Raciais no Brasil: um BalançO da Intervenção Governamental. Brasília: Instituto de Pesquisa Econômica Aplicada (IPEA), 2002.

38. JACCOUD, L. O combate ao racismo e à desigualdade: o desafio das políticas públicas de promoção da igualdade racial. In: THEODORO, M. et al. As políticas públicas e a desigualdade racial no Brasil 120 anos após a abolição, p.131165. Brasília: IPEA, 2009.

39. KIJIMA, Y. Caste and Tribe Inequality: Evidence from India, 1983-1999. Economic Development and Cultural Change, 54 (2), p. 369-405, 2006. 
40. KUMAR, D. The Affirmative Action Debate in India. Asian Survey, 32 (3), may, p. 290-302, 1992.

41. LAMOUNIER, B. Prefácio. In: FRY, P. (Orgs). Divisões Perigosas: Políticas Raciais no Brasil Contemporâneo. Rio de Janeiro: Civilização Brasileira, p. 9-11, 2007.

42. LUTOSA, I. Excesso de cor. In: FRY, P. (Orgs). Divisões Perigosas: Políticas Raciais no Brasil Contemporâneo. Rio de Janeiro: Civilização Brasileira, p. 137144, 2007.

43. MAGGIE, Y. Aqueles a quem foi negada a luz do dia: as categorias cor e raça na cultura brasileira. In: MAIO, M.C.; SANTOS, R.V.(Eds.). Raça, ciência e sociedade. Rio de Janeiro: Fiocruz, 1996.

44. MAGNOLI, D. Abolição da abolição. In: FRY, P. et al. (Orgs). Divisões Perigosas: Políticas Raciais no Brasil Contemporâneo. Rio de Janeiro: Civilização Brasileira, p. 63-66, 2007.

45. MAIO, M.C. Uma Polêmica Esquecida: Costa Pinto, Guerreiro Ramos e o Tema das Relações Raciais. Dados, 40(1), 1997.

46. MCMILLAN, A. Standing at the Margins - Representation and Electoral Reservation in India. Delhi: Oxford University Press, 2005.

47. MITRA, S.K. Caste, democracy and the politics of community formation in India. In: SEARLE, C.; SHARMA (Orgs.). Contextualising Caste: Post-Dumontian Approaches. Oxford: Blackwell Publishers, p. 49-70, 1994.

48. NANDA, B.R. Gandhi and His Critics. New Delhi: Oxford University Press, 2007.

49. OMYEDT, G. The Anti-Caste Movement and the Discourse of Power. In: $\mathrm{SHAH}, \mathrm{G}$. (org.) Caste and Democratic Politics in India. New Delhi: Permanent Black, p. 413-431, 2002.

50. OSÓRIO, R.G. O sistema classificatório de 'cor ou raça' do IBGE: Texto para discussão IPEA, 2003.

51. PANANDIKER, V.A.P. The Politics of Backwardness - Reservation Policy in India. New Delhi: Konark Publishers PVT LTD, 1997.

52. PARIKH, S. The politics of preference: democratic institutions and affirmative action in the United States and India. Michigan: The University of Michigan Press, 1997.

53. PAIXÃO, M. et al. Relatório Anual das Desigualdades Raciais no Brasil 2009-2010: Constituição Cidadã, seguridade social e seus efeitos sobre as assimetrias de cor ou raça, Observatório da Cidadania - Social Watch. Rio de Janeiro: Garamond, 2010. 
54. PENA, S. Ciências, bruxas e raças. In: FRY, P. et al. (orgs). Divisões Perigosas: Políticas Raciais no Brasil Contemporâneo. Rio de Janeiro: Editora Civilização Brasileira, p. 43-48, 2007

55. PINTO DE GOÉS, J.R; FLORENTINO, M. Parentesco e Família entre os Escravos no Século XIX: Um Estudo de Caso. Revista Brasileira de Estudos da População (12), p. 151-167, 1995.

56. PINTO DE GOÉS, J.R. Histórias mal contadas. In: FRY, P. et al. (orgs). Divisões Perigosas: Políticas Raciais no Brasil Contemporâneo. Rio de Janeiro: Editora Civilização Brasileira, p. 57-62, 2007.

57. PRAKASH, S. Reservations Policy for Other Backward Classes: Problems and Perspectives. In: PANANDIKER, V.A.P. The Politics of Backwardness - Reservation Policy in India. New Delhi: Konark Publishers PVT LTD, p. 29-82, 1997.

58. PREWITT, K. Presidential Items. Items, 50(1), march, 1996.

59. RANADIVE, B.T. Caste, Class and Property Relations. In: SHAH, G (org.) Caste and Democratic Politics in India. New Delhi: Permanent Black, pp. 134161, 2002.

60. RAJALAKSHMI, T.K.; TRIPATHI, P.S.. For and against, with reservations. Frontline, 25 (9), 2008.

61. ROBINSON, J.A.O. (Ed.). Affirmative action: a documentary history. Westport: Greenwood Press, 2001.

62. SCHWARTZMAN, S. Das estatísticas de cor ao estatuto da raça. In: FRY, P.et al.(orgs). Divisões Perigosas: Políticas Raciais no Brasil Contemporâneo. Rio de Janeiro: Editora Civilização Brasileira, p. 105-110, 2007.

63. SEN, A. Desigualdade Reexaminada. Rio de Janeiro: Record, 2001.

64. SEN, A. The Argumentative Indian - Writings on Indian Culture, History and Identity. Londres: Penguin Books, 2005.

65. SHAH, G. Caste and Democratic Politics in India. New Delhi: Permanent Black

66. SHETH, D.L. Caste and Class: Social Reality and Political Representations. In SHAH, G. Caste and Democratic Politics in India. New Delhi: Permanent Black, p. 209-233, 2002.

67. SHOURIE, A. Falling over backwards: an essay against reservations and against judicial populism. New Delhi: Rupa \& Co, 2006.

68. SILVA, N.V. Updating the cost of not being white in Brazil. In: HASENBALG, C.A. (Ed.), Race and socioeconomic inequalities in Brazil. Rio de Janeiro: IUPERJ, 1983. 
69. SKIDMORE, T. Preto no branco. Raça e nacionalidade no pensamento brasileiro. Rio de Janeiro: Paz \& Terra, 1976.

70. SRINIVAS, M.N. The Caste System in India. In: BÉTEILLE, A. (org.). Social Inequality - Selected Readings. Middlesex: Penguin Books, p. 79-89, 1969.

71. TUMMALA, K.K. Policy of Preference: Lessons from India, The United States, and South Africa. Public Administration Review, 59, 1999.

72. UOL. Brasileiros apoiam cotas raciais em universidades. Disponível em: http://noticias.uol.com.br/ultnot/brasil/2006/07/23/ult1928u2262.jhtm. 2006. Acesso em 23/07/2006.

73. VAINFAS, R. Racismo à moda americana. In: FRY, P. et al.(orgs). Divisões Perigosas: Políticas Raciais no Brasil Contemporâneo. Rio de Janeiro: Civilização Brasileira, p. 83-88, 2007.

74. VENTURA SANTOS, R. A obra de Euclides da Cunha e os debates sobre mestiçagem no Brasil no início do século XX: Os Sertões e a medicina-antropologia do Museu Nacional. História, Ciências, Saúde-Manguinhos, v.5, p. 237-254, 1998.

75. WEISSKOPF, T.E. Affirmative Action in the United States and India. Londres: Routledge, 2004.

76. WOOD, J.R. Reservations in Doubt: The Backlash Against Affirmative Action in Gujarat, India'. Pacific Affairs, V.60, p.408-430, 1987.

77. WRIGHT, T. A New Demand for Muslim Reservations in India. Asian Survey, V.37 (9), p.852-858, 1997.

78. ZAHUR, G. Aprendizes de feiticeiro. In: FRY, P. et al. (orgs). Divisões Perigosas: Políticas Raciais no Brasil Contemporâneo. Rio de Janeiro: Civilização Brasileira, pp. 127-132, 2007.

Recebido: 27/05/2015

Aceite final: 01/07/2015 